\title{
A RESPONSABILIDADE CIVIL DECORRENTE DA NÃO OBSERVÂNCIA DO PRINCÍPIO DA CONFIANÇA NAS RELAÇÕES DE FILIAÇÃO
}

\author{
CIVIL LIABILITY ENSUING FROM FAILURE TO COMPLY THE TENET OF TRUST IN \\ PARENT'S-CHILD RELATIONSHIPS.
}

Recebido: 10.03 .2020

Aprovado: 14.03 .2020

\author{
Joanemily Maria Ribeiro Alves \\ Mestranda pela Universidade Salvador. Pós- \\ graduanda em responsabilidade civil e direito do \\ consumidor pela Universidade de Fortaleza. \\ Advogada. \\ EMAIL: joane.malves@hotmail. \\ LATTES: http:/ /lattes.cnpq.br/7734829249491658 \\ ORCID: http://orcid.org/0000-0002-5627-7004
}

\author{
David Carneiro dos Anjos \\ Pós-graduando em responsabilidade civil e direito \\ do consumidor pela Universidade de Fortaleza. \\ Advogado. \\ EMAIL: david-carneiro@hotmail.com \\ LATTES: http:/ / lattes.cnpq.br/5458279412967142 \\ ORCID: https://orcid.org/0000-0003-0402-7289
}

\begin{abstract}
RESUMO: O presente artigo irá tratar da responsabilidade dos pais em relação aos filhos menores: abandono afetivo. Inicia-se, o estudo observando o poder familiar como um conjunto de direitos e deveres atribuído aos pais na formação e criação dos filhos, buscando sempre o melhor para eles. O trabalho encontra-se pautado no método teórico descritivo, fazendo-o através de um estudo doutrinários, jurisprudencial e legislativo. Iremos expor as penalidades existentes no Estatuto da Criança e Adolescente e Código Civil. Trazer à discussão a problemática suscitada neste trabalho, assim, observou se: A aplicação de penas pecuniárias é eficaz como meio de aproximação de pais e filhos? Por fim, iremos enfatizar o caráter pedagógico da reparação, mostrando a importância da convivência familiar para formação do caráter da criança/adolescente.
\end{abstract}

PALAVRAS-CHAVE: Responsabilidade Civil; Poder Familiar; Princípio da Confiança; Criança e Adolescente.

\begin{abstract}
This article will deal with the responsibility of parents in relation to minor children: affective abandonment. The study begins by observing family power as a set of rights and duties attributed to parents in the formation and rearing of their children, always seeking the best for them. The work is based on the descriptive theoretical method, doing so through a doctrinal, jurisprudential and legislative study. We will expose the penalties in the Child and Adolescent Statute and Civil Code. Bringing to the discussion the problem raised in this work, thus, he observed if: Is the application of pecuniary penalties effective as a means of bringing parents and children closer together? Finally, we will emphasize the pedagogical character of reparation, showing the importance of family coexistence for the formation of the character of the child/adolescent.
\end{abstract}


KEYWORDS: Civil Liability; Family Power; Tenet oftrust; Childand teenagers

SUMÁRIO: 1 Introdução 2 Do poder familiar 2.1 Dos deveres recorrentes do poder familiar 2.2 Do Princípio da confiança 3 A Responsabilidade civil na relação paterno filial 3.1 A teoria do abuso de direito e a não observância do poder familiar 3.2 A consequência do abandono do filho menor 4 Conclusões 5 Referências

\section{Introdução}

Desde o início das civilizações, já se tem internalizado a importância das famílias. A Constituição federal brasileira de 1988 deu ênfase a esta temática ao estipular ser a família a base da sociedade dando-Ihe proteção especial pelo Estado. A responsabilização civil no âmbito do direito das famílias é matéria a ser estudada, ao modo que as demandas vão surgindo, vindo a doutrina a contribuir bastante para este diálogo e para se firmar um entendimento de possibilidade de utilização desse instituto.

A dissolução da sociedade conjugal pode trazer inúmeros prejuízos nas relações entre pais e filhos comprometendo o desenvolvimento da criança. No panorama jurídico atual, pautado pela paternidade responsável, não se tolera que os filhos sejam tratados como mero instrumento de vingança. É neste contexto que se fixa a ideia dos doutrinadores contemporâneos de poder familiar.

Percebe-se um aumento considerável de ações ajuizadas nos tribunais brasileiros, pleiteando uma indenização pecuniária que repare o dano moral sofrido pelos filhos em razão do abandono ou abuso de direito por seus genitores. Trabalhar este tema é necessário para que haja melhora no estado emocional do indivíduo, que pleiteia uma indenização justa, educativa e punitiva em desfavor do requerido.

\section{Do Poder Familiar}

O poder familiar é um instituto que geram direitos e deveres atribuídos aos pais, em igualdade de condição, em relação à pessoa dos filhos e seus bens, objetivando a proteção destes.

Ainda sobre o conceito de poder familiar, este é um múnus público, ou seja, um direito função, imposto pelo Estado aos pais, com o fim de proteger o interesse dos filhos. Frisa-se, ainda, que o aludido instituto, é inalienável, imprescritível e irrenunciável ${ }^{1}$.

Maria Helena Diniz descreve o poder familiar como sendo um múnus público, competindo aos pais desempenhar este dever que a norma jurídica lhes impõe, reforçando o caráter impositivo da norma. ${ }^{2}$

A responsabilidade dos pais para com os filhos, vai desde a concepção até atingirem a maioridade. Como preceitua a Constituição federal brasileira de 1988, o planejamento familiar é de livre decisão do casal. Entretanto, é dever do Estado dar total proteção a família. Assim, o instituto em apreço nasce de uma necessidade natural: Nascidos os filhos, não basta alimentálos e deixá-los crescer à lei da natureza, há que educá-los e dirigi-los. ${ }^{3}$

1 GONÇALVES, Carlos Roberto. Direito de Família, p.396

2 DINIZ, Maria Helena. Direito de Família, p.553

3 GONÇALVES, Carlos Roberto. Direito de família, p.396 
O Código Civil de 2002 modificou a expressão pátrio poder para poder familiar, sendo este um conjunto de direitos e deveres exercido pelos pais quanto a formação e criação de seus filhos menores, em igualdade.

Preceitua a Constituição Federal de 1988,em seu art.226, §5ㅇ, que o poder familiar será exercido de forma simultânea por ambos os pais. Da mesma forma, disciplina o Código Civil, em seu art. 1631, parágrafo único, ou seja, que o poder familiar compete de forma igualitária aos pais e que no impedimento de um deles, o outro exercerá os poderes com exclusividade. $E$, se houver divergência, Ihes é assegurado recorrer ao Poder Judiciário para a solução do desacordo.

Na mesma linha de pensamento, o Estatuto da Criança e Adolescente traz no art.21 a seguinte redação; " O pátrio poder deve ser exercido em igualdade de condições, pelo pai e mãe, na forma que dispuser a legislação civil, assegurando a qualquer deles o direito de, em caso de discordância, recorrer à autoridade judiciária competente para a solução da divergência".

O instituto do pátrio poder foi criado para assegurar às crianças, jovens ou adolescentes advindas ou não da sociedade conjugal, reconhecidos ou adotivos, proteção integral aos seus direitos, tais como assistência, criação e educação.

\subsection{Dos Deveres Decorrentes do Poder Familiar}

O artigo 229 da CF/88 incube aos pais o dever de assistir, criar, educar os filhos menores. $\mathrm{O}$ artigo 1634 do CC, por sua vez, elenca os direitos e deveres dos pais, relativamente à pessoa dos filhos menores. Assim, é dever dos pais a criação, a educação, o sustento e os demais direitos dos filhos que são desmembramentos desses deveres maiores.

Cabe aos pais preparar os filhos para viver em sociedade, oferecendo meios materiais para sua subsistência, conforme seus recursos. Incube aos pais não só o dever de sustento, mas também o dever de educar para que seu filho seja útil para a sociedade, ou seja, auxiliar a criança ou adolescente na formação de seu caráter. A educação é a formação moral e também a escolar.

Cabe-Ihes ainda dirigir espiritual e moralmente o filho menor, dando-lhe uma formação religiosa, conforme preleciona Maria Helena Diniz ${ }^{4}$. Importante lembrar que o descumprimento a este dever poderá ensejar no crime de abandono material ou intelectual, ambos previstos no código penal, nos arts. 244 e 246.

Cabe aos pais o exercício efetivo da guarda que deve ser exercido por ambos os genitores. O dever de guarda impõe aos pais a responsabilidade civil pelo ato ilícito danoso praticado pelo filho menor. Dispõe o art. 932, I do CC, que " o direito de guarda é necessário para que possa exercer sobre ele a necessária vigilância". A jurisprudência tem decidido de forma que só poderá ser responsabilizado o pai que, no momento do ato ilícito danoso, tiver a efetiva guarda do filho.

DIREITO CIVIL. RESPONSABILIDADE CIVIL POR FATO DE OUTREM - PAIS PELOS ATOS PRATICADOS PELOS FILHOS MENORES. ATO ILÍCITO COMETIDO POR MENOR. RESPONSABILIDADE CIVIL MITIGADA E SUBSIDIÁRIA DO INCAPAZ PELOS SEUS ATOS (CC, ART. 928). LITISCONSÓRCIO NECESSÁRIO. INOCORRÊNCIA. 1. A responsabilidade civil do incapaz pela reparação dos danos é subsidiária e mitigada (CC, art. 928). 2. É subsidiária porque apenas ocorrerá quando os seus 
genitores não tiverem meios para ressarcir a vítima; é condicional e mitigada porque não poderá ultrapassar o limite humanitário do patrimônio mínimo do infante (CC, art. 928, par. único e En. 39/CJF); e deve ser equitativa, tendo em vista que a indenização deverá ser equânime, sem a privação do mínimo necessário para a sobrevivência digna do incapaz (CC, art. 928, par. único e En. 449/CJF). 3. Não há litisconsórcio passivo necessário, pois não há obrigação - nem legal, nem por força da relação jurídica (unitária) - da vítima lesada em litigar contra o responsável e o incapaz. É possível, no entanto, que o autor, por sua opção e liberalidade, tendo em conta que os direitos ou obrigações derivarem do mesmo fundamento de fato ou de direito (CPC,73, art. 46, II) intente ação contra ambos - pai e filho -, formandose um litisconsórcio facultativo e simples. 4. O art. 932, I do CC ao se referir a autoridade e companhia dos pais em relação aos filhos, quis explicitar o poder familiar (a autoridade parental não se esgota na guarda), compreendendo um plexo de deveres como, proteção, cuidado, educação, informação, afeto, dentre outros, independentemente da vigilância investigativa e diária, sendo irrelevante a proximidade física no momento em que os menores venham a causar danos. 5. Recurso especial não provido. (STJ - REsp: 1436401 MG 2013/0351714-7, Relator: Ministro LUIS FELIPE SALOMÃO, Data de Julgamento: 02/02/2017, T4 - QUARTA TURMA, Data de Publicação: DJe 16/03/2017)

A responsabilidade pelos atos ilícitos dos filhos menores, conforme o julgado supramencionado recai sobre aqueles que detêm a obrigação de vigilância, sendo destes inicialmente o dever de indenizar e somente de forma subsidiária dos primeiros quando possuírem patrimônio.

Deste modo, vê-se uma clara disposição da jurisprudência em firmar a tese de que incumbe aos genitores ou a aquele que exerça a guarda o compromisso de estar atento aos atos que os menores venham a praticar, levando-se em conta a sua situação de ser humano em desenvolvimento.

Também é dever dos pais a concessão do consentimento para casar. Ninguém melhor que os pais para dar ou negar autorização para matrimônio. O consentimento deve ser específico, ou seja, os genitores aprovam o casamento do filho com um sujeito determinado e não para casar-se com qualquer pessoa.

Outro dever dos pais é conceder ou negar consentimento para que os filhos possam viajar ao exterior. As situações que necessitam de autorização dos pais para viagens estão elencadas no ECA, artigo 83: "nenhuma criança poderá viajar para fora da comarca onde reside, desacompanhada dos pais ou responsável, sem expressa autorização judicial".

Entretanto, por determinação do CNJ, no Art. 10 da Resolução no 131, de 26 de maio de 2011, é dispensável a autorização judicial para que crianças ou adolescentes brasileiros residentes no Brasil viajem ao exterior se em companhia de ambos os genitores ou em companhia de um dos genitores, desde que haja autorização do outro, com firma reconhecida, 
assim como desacompanhado ou em companhia de terceiros maiores e capazes, designados pelos genitores, desde que haja autorização de ambos os pais, com firma reconhecida.

Também cabe aos pais conceder ou negar consentimento para os filhos mudarem sua residência permanente para outro Município, uma vez que os incapazes necessitam de domicílio determinado, que em regra é o mesmo dos pais. Esta determinação legal somada ao direito de guarda e o direito dos pais de manter os filhos em sua companhia, permite que os responsáveis legais escolham o local mais adequado como domicílio dos menores.

Outra incumbência dos pais é a nomeação de tutor por testamento ou documento autêntico, se o outro dos pais não lhe sobreviver, ou o sobrevivo não puder exercer o poder familiar. Este Instituto é conhecido como tutela testamentária, que na verdade não é um dever, mas uma faculdade atribuída aos pais. Ocorre quando, em testamento, o genitor escolhe um tutor para deixar a guarda de seu filho. Uma ressalva que se deve fazer é que este instituto só será válido caso o outro cônjuge for morto ou não poder exercer o poder familiar.

Havendo necessidade, deve os pais representar judicial e extrajudicialmente os filhos até os 16 (dezesseis) anos, nos atos da vida civil, e assisti-los, após essa idade, nos atos em que forem partes, suprindo-lhes o consentimento.

O código civil disciplina os dois tipos de incapacidade existente no direito brasileiro. A incapacidade absoluta impede que o menor exerça atos da vida civil, por si só e caso não seja observado o ato será nulo. A incapacidade relativa permite que o incapaz pratique atos da vida civil, desde que assistido, sob pena de anulabilidade. Ambas as incapacidades citadas, são supridas, pela representação do filho do nascimento até os 16 anos e no caso da assistência dos 16 até completar os 18 anos, quando atingirá a maior idade e estará apto a prática de atos da vida civil.

Deve os pais reclamar os filhos de quem ilegalmente os detenha. É um direito dos filhos e dever dos pais manter seus filhos sob sua guarda e proteção. Caso alguém os detenha, cabe impetrar a ação de busca e apreensão, no caso de ter este direito cerceado por um terceiro que não seja os detentores da guarda.

Por fim, o filho necessita cooperar com o pai, para que este possa exercer seu poder sobre o filho. A relação pai e filho é uma relação de hierarquia. Com o advento do Estatuto da Criança e Adolescente, o menor passou a ser tratado como um ser detentor de direitos e não mais como uma coisa. Para tanto os pais de forma moderada podem castigar o filho, mas respeitando sua integridade física, psíquica e moral. A aplicação de castigos imoderados caracteriza o crime de maus-tratos, tipificado no art. 136 do Código Penal, configurando uma das possibilidades de perda do poder familiar. ${ }^{6}$

\subsection{Princípio da Confiança}

Nos dizeres de Fernanda Tartuce (2014, online), "confiar é acreditar (credere), é manter, com fé (fides) e fidelidade, a conduta, as escolhas e o meio; confiança é aparência, informação, transparência, diligência e ética no exteriorizar vontades".

A confiança é um elemento essencial no âmbito das relações familiares, que, com o advento da Constituição Federal de 1988, recebeu especial proteção da ordem jurídica vigente, conforme se depreende da simples leitura dos artigos 226 a 230, ao fenômeno jurídico que se

8 Art. 136 - Expor a perigo a vida ou a saúde de pessoa sob sua autoridade guarda ou vigilância, para fim de educação, ensino, tratamento ou custódia, quer privando-a de alimentação ou cuidados indispensáveis, quer sujeitando-a a trabalho excessivo ou inadequado, quer abusando de meios de correção ou disciplina: 
denomina como verticalização das normas constitucionais ou constitucionalização do Direito de Família.

Desta maneira, a família fora reconhecida constitucionalmente como entidade tendente a promover o desenvolvimento da personalidade de seus membros, pautando-se de forma precípua no afeto e na solidariedade, refutando-se o falido individualismo e o enfoque patrimonial. (Dias, 2017, online).

Neste sentido, tem-se que a tutela da confiança atua de forma a superar a teoria da declaração, por meio da qual o enfoque dos negócios jurídicos residia unicamente na declaração de vontade dos envolvidos, ignorando-se os aspectos psíquicos destes, bem como a teoria da vontade, onde há predominância da vontade interna das partes em detrimento das declarações, segundo Cristiano Chaves de Farias (2017, online), "é o ser superando o ter".

Tal alteração se afigura como uma relevante mudança de paradigma na ordem jurídica constitucional, porquanto, a partir de então, a tutela ou princípio da confiança passou a nortear as relações jurídicas, incluindo-se como vetor preponderante destas, a noção de isonomia entre as partes, bem como determinando-se a observância da boa-fé e da solidariedade social.

No que diz respeito a sua aplicação no Direito de Família, a tutela da confiança atua como um corolário da teoria pós-moderna, consubstanciando-se, basicamente, na vedação de condutas contraditórias (venire contra factumproprium) dentro do convívio familiar, objetivando, pois, a efetividade dos deveres inerentes a tal modalidade de vivência e estabelecendo-se que estas deverão pautar-se em observância ao que dispõe a transparência e a previsibilidade (TARTUCE, 2018, online).

Exemplo disto é o dever de prover os cuidados inerentes a prole, consubstanciado na lei constitucional vigente, como acima mencionado, bem como previsto em vários dispositivos infraconstitucionais, que, quando não efetivados, podem propiciar aplicação de inúmeras penalidades ou mesmo de medidas coercitivas, objetivando o cumprimento destes encargos, tais como: a suspensão ou perda do poder familiar ou mesmo a decretação da prisão civil do devedor de alimentos.

Este é o viés que o presente estudo se propõe a discutir, ou seja, acerca da inobservância do princípio da confiança nas relações familiares, tendo este duas perspectivas, quais sejam: a confiança quando destinada as relações subjetivas, sob o fundamento do afeto e a confiança no que diz respeito as relações objetivas, ou seja, patrimonial (CHAVES, 2017, online).

Assim, superando-se o conceito do referido instituto, destaca-se que nos tópicos seguintes deste estudo, serão explanados, de forma detida, os desdobramentos da desobediência a tutela ou princípio da confiança nas relações patrimonial e de afeto com enfoque no que nos deveres inerentes ao convívio paterno filiar.

\section{A Responsabilidade Civil na Relação Paterno Filial}

Como delineado no primeiro tópico deste estudo, o poder familiar pressupõe a observância de alguns deveres, ou como destaca Carlos Roberto Gonçalves (2017, pag. 410), "o instituto em apreço resulta de uma necessidade natural. Constituída a Família e nascido os filhos, não basta alimentá-los e deixá-los crescer a lei da natureza, como os animais inferiores. Há que educá-los e dirigi-los".

É cediço que durante a infância e adolescência, em razão da condição de constante desenvolvimento, seja no aspecto físico ou mesmo emocional, o ser humano necessita de alguém que o crie, eduque, ampare, defenda e guarde seus interesses, afetivos ou mesmo patrimoniais. Tal incumbência, precipuamente, é destinada aos genitores, como estabelecem o Código Civil e a Constituição Federal nos dispositivos já mencionados acima. 
Em sendo assim, tem-se que o não cumprimento destas obrigações poderão, consequentemente, ensejar a aplicação do instituto da responsabilidade civil, desde que, por óbvio, estejam presentes os elementos tradicionais que caracterizam o dever reparatório, quais sejam: o dano, a conduta ilícita, a culpa e o nexo de causalidade, conforme explanado de forma detalhada anteriormente no tópico 1.4 .

Assim, no presente tópico serão abordados a teoria do abuso de direito e a não observância do poder familiar, bem como as consequências jurídicas provenientes do abandono familiar.

\title{
3.1 A Teoria do Abuso De Direito e a não Observância do Poder Familiar
}

O abuso de direito é uma categoria geral do sistema e da ciência jurídica, como ocorre no exercício arbitrário das próprias razões no Direito penal ou mesmo na litigância de má-fé no Processo Civil, consistindo, pois, na má ou deturpada utilização de uma faculdade conferida, isto é, no emprego anormal da posição jurídica ocupada ou no desvio de sua finalidade.

Infere-se assim, que os institutos jurídicos possuem finalidades parciais, observando-se alcançar as finalidades gerais determinadas pelo ordenamento com um todo, de modo que, os desvios a estes, implicam na prática de atos ilícitos, considerando-se assim, o sentido mais amplo do termo e em observância ao que dispõe o art. 187 do Código Civil ${ }^{7}$.

Neste sentido, refere Rolf Madaleno acerca do abuso de Direito (2017, pag. 1032)

\begin{abstract}
"Pretensamente amparado na ideia de exercer um direito subjetivo, dele exorbita o seu titular e com este gesto ingressa no campo da ilicitude, ao violar, em verdade, com seu excesso, o direito de outrem, e neste caso o Código Civil impõe, como fundamental dever do cidadão, agir com lealdade, correção e boa-fé.

O uso abusivo de um direito em qualquer esfera de atuação gera diversos efeitos, como o do dever de indenizar pelo ato ilícito, pela reposição da situação anterior, mas tudo dependendo da formulação utilizada para abusar de um direito, sem descurar que a disposição contida no artigo 187 do Código Civil é de ordem pública, inderrogável pela vontade das partes, podendo ser conhecida de ofício pelo juiz em qualquer grau de jurisdição."
\end{abstract}

Desta maneira, analisar-se-á a aplicação particular deste instituto no âmbito do poder familiar, compreendendo-se como abusivas as situações nas quais os detentores deste poderdever excedem as balizas socialmente esperadas de sua atuação e desviam-se das finalidades jurídicas associadas à sua condição de pais, incluindo-se também todos aqueles que ocupam posições juridicamente assemelhadas, tai como guardiões, tutores e curadores (TARTUCE, 2014, online).

Logo, tem-se que o direito das famílias é campo fecundo para aplicação da teoria do abuso de direito, principalmente, quando se analisa a inobservância dos deveres inerentes ao poder familiar, cuja atuação nos tempos hodiernos se baseia na dualidade: autonomia e responsabilidade, possuindo, pois, como elo central o afeto e a solidariedade.

Por esse ângulo, preleciona Flávio Tartuce acerca da teoria do abuso de direito quando da inobservância do poder familiar (2017, pag. 538):

7Art. 187. Também comete ato ilícito o titular de um direito que, ao exercê-lo, excede manifestamente os limites impostos pelo seu fim econômico ou social, pela boa-fé ou pelos bons costumes. 
"Havendo abusos nesse exercício, estará configurado o abuso de direito, - que pode repercutir, em casos de danos, na esfera da responsabilidade civil (arts. 187 e 927 do CC). Como consequência, além da suspensão ou destituição do poder familiar, o pai ou a mãe poderá ser condenado a pagar indenização por danos morais aos filhos se os maus-tratos estiverem presentes. Lembre-se de que como parâmetros para o abuso de direito devem ser considerados os previstos no art. 187 do CC, que são verdadeiras cláusulas gerais: fim social, boa-fé objetiva e, principalmente, bons costumes; o que gera a responsabilidade objetiva do pai ou mãe abusador (Enunciado n. 37 do CJF/STJ)."

Vê-se que a aplicação da teoria do abuso de direito nestes casos poderá ensejar a suspensão ou até mesmo a perda do poder familiar, consequências previstas no art. 1.637 e 1.638 do Código Civil $^{8}$, bem como a incidência do instituto da responsabilidade civil, culminando no dever reparar o dano morais experimentados pelos prejudicados mediante o adimplemento de indenização.

A título exemplificativo entende-se como situações que configuram abuso de poder no âmbito do poder familiar: no exercício do direito de visitas, quando o genitor abusa da custódia e impede a comunicação do outro ascendente ou do visitante quando abusa do direito do filho ser visitado e não comparece no dia da visita; ou, se as visitas são exercidas pelos avós, as nega ou dificulta ou mesmo na fixação do domicílio o ascendente-guardião da prole ao mudar para lugar distante ou de difícil acesso, para dificultar o direito do visitador (MADALENO, 2017, Pag. 302).

Ademais, entende-se que o abandono, seja este afetivo ou ainda material, poderá também ser caracterizado como abuso de direito, porquanto há desobediência flagrante ao que dispõe o dever de prover há um verdadeiro descumprimento ao que preconiza o direito de convivência família, esculpido no art. 1.632 do Diploma Civil, incendiando ainda em afronta ao que estabelece o princípio constitucional da proteção integral.

Deste modo, verifica-se que a aplicação da teoria do abuso de direito pode ser vista de forma ampla nas relações paterno filiar, em virtude da nova concepção de família oportunizada pela constituição federal de 1988, que, sobretudo, confere maior proteção as crianças e adolescentes, alterando assim, o paradigma dos filhos enquanto propriedades, passando-se a

\footnotetext{
8 Art. 1.637. Se o pai, ou a mãe, abusar de sua autoridade, faltando aos deveres a eles inerentes ou arruinando os bens dos filhos, cabe ao juiz, requerendo algum parente, ou o Ministério Público, adotar a medida que lhe pareça reclamada pela segurança do menor e seus haveres, até suspendendo o poder familiar, quando convenha.

Parágrafo único. Suspende-se igualmente o exercício do poder familiar ao pai ou à mãe condenados por sentença irrecorrível, em virtude de crime cuja pena exceda a dois anos de prisão.

Art. 1.638. Perderá por ato judicial o poder familiar o pai ou a mãe que: I - castigar imoderadamente o filho; II deixar o filho em abandono; III - praticar atos contrários à moral e aos bons costumes; IV - incidir, reiteradamente, nas faltas previstas no artigo antecedente.

V - Entregar de forma irregular o filho a terceiros para fins de adoção. Parágrafo único. Perderá também por ato judicial o poder familiar aquele que: I - praticar contra outrem igualmente titular do mesmo poder familiar: a) homicídio, feminicídio ou lesão corporal de natureza grave ou seguida de morte, quando se tratar de crime doloso envolvendo violência doméstica e familiar ou menosprezo ou discriminação à condição de mulher; b) estupro ou outro crime contra a dignidade sexual sujeito à pena de reclusão;

II - Praticar contra filho, filha ou outro descendente: a) homicídio, feminicídio ou lesão corporal de natureza grave ou seguida de morte, quando se tratar de crime doloso envolvendo violência doméstica e familiar ou menosprezo ou discriminação à condição de mulher; b) estupro, estupro de vulnerável ou outro crime contra a dignidade sexual sujeito à pena de reclusão.
} 
percebê-los então enquanto seres em situação de excepcional desenvolvimento, merecendo, pois, amparo e zelo dos seus, suas consequências, serão melhor tratadas no próximo sub tópico.

48 | Revista do Programa de Pós-Graduação em Direito da UFBA, e-issn 2358-4777, v. 30, n. 01, p.40 -54, Jan-Jun 2020 


\title{
3.2 A Consequência do Abandono do Filho Menor
}

O abandono consiste no desamparo afetivo, intelectual ou material de quem precipuamente teria o dever de provê-los. Logo, conforme já suscitado anteriormente, tal desídia importará na incidência de algumas consequências, sendo estas tanto no âmbito do Direito Civil, quanto do Direito Penal.

Acerca das consequências do abandono do poder familiar, diz Carlos Roberto Gonçalves (2017, pág. 426):

\begin{abstract}
"Prevê o art. 227 da Constituição Federal que a criança e o adolescente têm direito à convivência familiar e comunitária". O abandono priva o filho desse direito, além de prejudicá-lo em diversos sentidos. A falta de assistência material coloca em risco a sua saúde e sobrevivência, mas não constitui a única forma de abandono. Este pode ser também moral e intelectual, quando importa em descaso com a educação e moralidade do infante. O Código Penal, visando reprimir as diversas formas de abandono de filho, prevê os crimes de 'abandono material' ( $C P$, art. 244), 'abandono intelectual' (art. 245), 'abandono moral' (art. 247), 'abandono de incapaz' (art. 133), abandono de recém-nascido' (art. 134)."
\end{abstract}

Dispõe o Código civil em seu art. 1.638, inciso II, que deixar o filho em situação de abandono configura hipótese hábil a ensejar a perda do poder familiar, constituindo, assim, o tipo mais grave de destituição, a ser determinada por decisão judicial e por consequência, acarretará na extinção deste poder conforme preconiza o art. 1.635 , inciso $\mathrm{V}^{9}$ do mesmo regramento.

Assim, constatando-se a ocorrência de danos aos indivíduos cujos cuidados deveriam ter sido expedidos, tendo, ao revés, sido mantidos em abandono por seus genitores ou mesmo por aqueles que detinham tal incumbência, no instituto da Tutela ou ainda nas hipóteses de Guarda excepcional, verifica-se a possibilidade de aplicação dos institutos que dizem respeito responsabilidade civil, surgindo-se, então, o dever de reparar.

Para a efetiva reparação civil será necessária a demonstração da ocorrência efetiva do dano, embasando-se nos efeitos nefastos produzidos pelo abandono no desenvolvimento psicossocial do indivíduo lesionado. Nesta esteira se posiciona a jurisprudência pátria acerca da temática:

APELAÇÃO CÍVEL. ECA. DESTITUIÇÃO DO PODER FAMILIAR CUMULADA COM ADOÇÃO. CRIANÇA EM SITUAÇÃO DE VULNERABILIDADE, ABANDONADA, ENTREGUE A TERCEIROS PELOS GENITORES, QUE SE EXIMIRAM DAS OBRIGAÇÕES DE PARENTALIDADE. COLOCAÇÃO EM FAMÍLIA SUBSTITUTA NA MODALIDADE DE ADOÇÃO FAMÍLIA EXTENSA. POSSIBILIDADE. SENTENÇA MANTIDA. Caso dos autos em que o infante foi deixado pelos genitores aos cuidados de pessoas da família extensa, eximindo-se dos deveres inerentes ao poder familiar, caracterizando o abandono afetivo e material. Prova dos autos evidenciando o abandono

9 Art. 1.635. Extingue-se o poder familiar: I - pela morte dos pais ou do filho; II - pela emancipação, nos termos do art. $5^{\circ}$, parágrafo único; III - pela maioridade; IV - pela adoção; $V$ - por decisão judicial, na forma do artigo 1.638 . 
e a incapacidade dos genitores para exercerem adequadamente os deveres parentais. Guardiões (tios paternos) que garantiram ao infante desenvolvimento saudável e pleno, estabelecendo vínculos de afeto sólidos, sendo reconhecidos pela criança como seus pais, desde tenra idade. Sentença de primeira instância que não merece ser modificada, sendo mantida a destituição do poder familiar em relação a ambos os genitores, com a confirmação da adoção do infante aos autores da ação. Recurso desprovido. (Apelação Cível № 70079627089, Oitava Câmara Cível, Tribunal de Justiça do RS, Relator: José Antônio Daltoe Cezar, Julgado em 28/02/2019).

(TJ-RS - AC: 70079627089 RS, Relator: José Antônio Daltoe Cezar, Data de Julgamento: 28/02/2019, Oitava Câmara Cível, Data de Publicação: Diário da Justiça do dia 08/03/2019) (BRASIL, 2019)

APELAÇÃO CÍVEL. AÇÃO DE INDENIZAÇÃO POR ABANDONO AFETIVO E MATERIAL CUMULADA COM ALIMENTOS. IMPROCEDÊNCIA NA ORIGEM. INSURGÊNCIA DA PARTE AUTORA RESTRITA À REPARAÇÃO CIVIL. ARGUMENTO NO SENTIDO DE QUE AS TESES CONSIGNADAS NA EXORDIAL, ALIADAS À REVELIA DO DEMANDADO, SERIAM SUFICIENTES À AUTORIZAR A RESPONSABILIZAÇÃO CIVIL PELO ABANDONO PRATICADO. INSUBSISTÊNCIA. ABSOLUTA AUSÊNCIA DE PROVAS A RESPEITO DO ATO ILÍCITO E DOS SUPOSTOS DANOS, EM AFRONTA AO QUE DISPÕE O ARTIGO 186 DO CÓDIGO CIVIL. REVELIA, ADEMAIS, QUE INDUZ A PRESUNÇÃO RELATIVA DOS FATOS. NECESSIDADE DE PROVA MÍNIMA PARA FORMAÇÃO DO CONVENCIMENTO DO MAGISTRADO. SENTENÇA MANTIDA. RECURSO DESPROVIDO.

(TJ-SC - AC: 03040249820168240064 São José 030402498.2016.8.24.0064, Relator: Raulino Jacó Brüning, Data de Julgamento: 13/06/2019, Primeira Câmara de Direito Civil) (BRASIL, 2019)

Há de se compreender que o abandono material ou afetivo será comprovado diante da análise do o caso, existindo, assim, um critério de dimensão a ser auferido pelo órgão julgador a fim de apurar a dimensão dos danos causados aqueles cujos cuidados ao desenvolvimento psicossocial deveriam ter sido despendidos.

Neste sentido, verifica-se entendimento firmado pelo STJ no Resp no $1.087 .561^{10}$, por meio do qual a corte posicionou-se favorável a condenação em danos morais, em virtude da ocorrência do abandono material reiterado. No caso em análise, o genitor possuía uma boa situação financeira, auxiliava os outros filhos de forma satisfativa e permitia que um dos filhos perpassem por dificuldades, não contribuindo para o seu sustento ou só arcando quando compelido pelas vias executórias.

A corte reverberou que constitui ilícito civil a atitude do genitor de não proporcionar ao filho condições dignas de sobrevivência, mesmo munido de bom aporte financeiro, causando a este, danos à integridade física, moral, intelectual e psicológica, o que, portanto, dá ensejo a necessidade de reparação civil.

O reconhecimento do dano moral não é a monetização da desídia nas relações paterna filial, mas, o reconhecimento, que o descumprimento de um preceito jurídico poderá acarretar

10A omissão voluntária e injustificada do pai quanto ao amparo MATERIAL do filho gera danos morais, passíveis de compensação pecuniária. STJ. 4ạ Turma. REsp 1.087.561-RS, Rel. Min. Raul Araújo, julgado em 13/6/2017 (Info 609) (BRASIL, 2017). 
danos aqueles os quais o direito de lhe era atribuído, sendo, por conseguinte, necessário buscar formas de reparar.

Pablo Stolze citado por Brenno Grilho aponta que responsabilizar civilmente por abandono material apenas baseado em atraso de pensão alimentícia não é fundamento suficiente. "É necessário, na linha do julgado, que esteja configurado o ilícito, sob pena de banalização da tese que, além de justa, visa a dar o mínimo amparo ao filho necessitado" (2017, online).

Quanto as consequências provenientes do abandono afetivo, a corte superior consolidou entendimento semelhante ao do caso anteriormente citado, no sentido de que sendo comprovada a ilicitude do ato e restando configurado o dano, há de se reconhecer o dever de indenizar por aquele que usurpou o poder familiar. Veja-se o fundamento adotado no Resp no 1.159.242-SP:

CIVIL E PROCESSUAL CIVIL. FAMÍLIA. ABANDONO AFETIVO. COMPENSAÇÃO POR DANO MORAL. POSSIBILIDADE.

1. Inexistem restrições legais à aplicação das regras concernentes à responsabilidade civil e o consequente dever de indenizar/compensar no Direito de Família.

2. O cuidado como valor jurídico objetivo está incorporado no ordenamento jurídico brasileiro não com essa expressão, mas com locuções e termos que manifestam suas diversas desinências, como se observa do art. 227 da CF/88.

3. Comprovar que a imposição legal de cuidar da prole foi descumprida implica em se reconhecer a ocorrência de ilicitude civil, sob a forma de omissão. Isso porque o non facere, que atinge um bem juridicamente tutelado, leia-se, o necessário dever de criação, educação e companhia de cuidado - importa em vulneração da imposição legal, exsurgindo, daí, a possibilidade de se pleitear compensação por danos morais por abandono psicológico.

4. Apesar das inúmeras hipóteses que minimizam a possibilidade de pleno cuidado de um dos genitores em relação à sua prole, existe um núcleo mínimo de cuidados parentais que, para além do mero cumprimento da lei, garantam aos filhos, ao menos quanto à afetividade, condições para uma adequada formação psicológica e inserção social.

5. A caracterização do abandono afetivo, a existência de excludentes ou, ainda, fatores atenuantes - por demandarem revolvimento de matéria fática - não podem ser objeto de reavaliação na estreita via do recurso especial.

6. A alteração do valor fixado a título de compensação por danos morais é possível, em recurso especial, nas hipóteses em que a quantia estipulada pelo Tribunal de origem revela-se irrisória ou exagerada.

7. Recurso especial parcialmente provido (BRASIL, 2019).

Portanto, verifica-se que o ordenamento jurídico elenca uma série de consequências destinada aos que incorrem no abandono familiar, estando a jurisprudência pátria firmando entendimentos no sentido da responsabilização civil em decorrência dos referidos ilícitos, desde que seja evidente ocorrência do dano, sem prejuízo das medidas judiciais previstas no Código Penal. 


\section{Conclusão}

O dever do Estado é proteger integralmente crianças e adolescentes, garantindo a satisfação dos seus direitos, inclusive no âmbito familiar. Por este motivo, pais que rejeitam e abandonam seus filhos causando danos a esfera íntima destes, devem ser condenados a contribuir para diminuição dos males que causaram.

As penas pecuniárias aplicadas aos pais têm caráter punitivo-educativo, ou seja, objetivam repreender a prática abusiva no caso concreto e desestimular a prática reiterada dos atos. Entretanto, não existe um piso mínimo e nem um máximo para o arbitramento da sanção. Assim fica a critério do magistrado estipular um valor razoável que possa atender ao caráter objetivado. $O$ valor arbitrado a título de indenização irá apenas amenizar os danos. $O$ amor não é impositivo, mas a criança tem todo direito ao convívio social saudável com os pais.

Apesar de o assunto ser extremamente delicado, a responsabilidade civil nas relações de família não é mais novidade no cenário jurídico atual. Conforme o código civil, aquele que causar dano a outrem deve responder! Embora o Poder Judiciário não possa garantir o amor, pode garantira convivência familiar e a preservação da dignidade do requerente.

O cerne da questão é inibir a prática de atos abusivos, educar os pais para assumirem uma paternidade responsável e para que entendam que seu papel é proteger, e preparar seus filhos para o convívio social. Um filho é para sempre. E enquanto menores precisam ter cuidado e precisão ser formados e educados para um convívio saudável com a sociedade.

\section{Referências}

BRASIL, Lei 10.406 de 10 JAN 2002. Institui o Código Civil. Disponivel em: <http://www.planalto.gov.br/ccivil_03/leis2002/I10406.htm>Acesso em 10 jan.2018.

BRASIL. Superior Tribunal de Justiça. Ementa № Resp № 1.087.561. Recurso Especial № 1.087.561 - Rs (2008/0201328-0). Brasilia, . Disponível em: <http://www.mpce.mp.br/wpcontent/uploads/2017/10/STJ-RECURSO-ESPECIAL.-FAM\%C3\%8DLIA.-ABANDONO-MATERIAL.MENOR.-DESCUMPRIMENTO-DO-DEVER-DE-PRESTAR-ASSIST\%C3\%8ANCIA-MATERIAL-AOFILHO.-REPARA\%C3\%87\%C3\%830.-DANOS-MORAIS.-POSSIBILIDADE.-RECURSOIMPROVIDO..pdf $>$. Acesso em: 20 jul. 2019.

BRASIL. Superior Tribunal de Justiça. Ementa no RECURSO ESPECIAL № 1.159.242 - SP (2009/0193701-9). Recurso Especial № 1.159.242 - Sp (2009/0193701-9). Disponível em: <https://www.migalhas.com.br/arquivo_artigo/art20120510-02.pdf>. Acesso em: 20 jul. 2019.

BRASIL. Tribunal de Justiça de Santa Catarina. Ementa no 03040249820168240064. Diário Oficial do Estado de Santa Catarina. Florianopolis, . Disponível em: <https://tjsc.jusbrasil.com.br/jurisprudencia/723809982/apelacao-civel-ac-3040249820168240064-saojose-0304024-9820168240064/inteiro-teor-723810032?ref=serp>. Acesso em: 30 jun. 2019.

BRASIL. Tribunal de Justiça do Rio Grande do Sul. Ementa no AC 70079627089 RS. Porto Alegre, RS, 28 de fevereiro de 2019. Diário Oficial do Estado do Rio Grande do Sul. Porto Alegre, . Disponível em: <https://tj-rs.jusbrasil.com.br/jurisprudencia/683354672/apelacao-civel-ac70079627089-rs/inteiro-teor-683354700?ref=juris-tabs>. Acesso em: 30 jun. 2019. 
BRASIL, Superior Tribunal de Justiça (Resp 1159242/SP, Rel. Ministra NANCY ANDRIGHI, TERCEIRA TURMA, julgado em 24/04/2012, Dje 10/05/2012)

DELMONDES, DienneStefanny Magalhães. Danos morais por Abandono Afetivo. F

DIAS, Maria Berenice. Os princípios da lealdade e da confiança na família. Disponível em: <http://www.mariaberenice.com.br/manager/arq/(cod2_564)18_os_principios_da_lealdade_e _da_confianca_na_familia.pdf $>$. Acesso em: 30 jun. 2019.

DINIZ, Maria Helena. Curso de Direito Civil Brasileiro: Responsabilidade Civil. 24. ed. São Paulo: Saraiva, 2010.

DINIZ, Maria Helena. Curso de Direito Civil Brasileiro: Direito da Família. 25. Ed. São Paulo: Saraiva, 2010.

FARIAS, Cristiano Chaves de. A tutela jurídica da confiança aplicada ao Direito de Família. Disponível em: <http://www.ibdfam.org.br/assets/upload/anais/11.pdf>. Acesso em: 30 jun. 2019.

FARIAS, Cristiano Chaves de; ROSENVALD, Nelson. Direito das Famílias. 2. ed. Rio de Janeiro: Lúmen Júris, 2010.

FARIAS, Cristiano Chaves de; ROSENVALD, Nelson; NETTO, Fellipe Peixoto Braga. Novo Tratado de Responsabilidade Civil. Ed. São Paulo: Atlas, 2015.

FILHO, Sérgio Cavalieri. Programa de Responsabilidade Civil. 9. Ed. São Paulo: Atlas, 2009.

GONÇALVES, Carlos Roberto. Direito Civil Brasileiro: Direito da Família. 6. 12a edição, Ed. São Paulo: Saraiva, 2017.

GONÇALVES, Carlos Roberto. Direito Civil Brasileiro: Responsabilidade Civil. 3. Ed. São Paulo: Saraiva, 2008.

GRAMSTRUP, Erik F.; TARTUCE, Fernanda. A responsabilidade civil pelo uso abusivo do poder familiar. Disponível em: <http://www.fernandatartuce.com.br/wp-content/uploads/2016/08/Aresp-civil-por-uso-abusivo-do-poder-familiar.pdf>. Acesso em: 30 jun. 2019.

GRILLO, Brenno. RELAÇÃO DISTANTE: STJ condena pai a indenizar filho em danos morais por abandono afetivo. Disponível em: <https://www.conjur.com.br/2017-nov-26/stj-condena-paiindenizar-filho-danos-morais-abandono>. Acesso em: 20 jul. 2019.

MADALENO, Rolf. Direito de Família. 7. ed. Rio de Janeiro: Forense Ltda, 2017. 1287 p.Fortaleza: Expressão Gráfica, 2012.

TARTUCE, Flavio. Direito Civil: Direito de Família. 14. ed. Rio de Janeiro: Forense Ltda, 2019. 767 p.

TARTUCE, Flávio. O PRINCÍPIO DA BOA-FÉ OBJETIVA NO DIREITO DE FAMÍLIA. Disponível em: <http://www.ibdfam.org.br/_img/congressos/anais/48.pdf>. Acesso em: 30 jun. 2019. 
TAVARES, José de Farias. Comentários ao Estatuto da Criança e do Adolescente. 7.ed. Rio de Janeiro: Forense, 2006.

54 | Revista do Programa de Pós-Graduação em Direito da UFBA, e-issn 2358-4777, v. 30, n. 01, p.40 -54, Jan-Jun 2020 